\title{
COVID-19, a critical juncture in China's wildlife protection?
}

\author{
Jing $\mathrm{Xu}^{1}{ }^{(\mathbb{D})} \cdot$ Fengqiao $\mathrm{Mei}^{2} \cdot$ Chuntian $\mathrm{Lu}^{1}$
}

Received: 30 December 2020 / Accepted: 16 March 2021 / Published online: 25 March 2021

(C) Springer Nature Switzerland AG 2021

\begin{abstract}
The COVID-19 crisis has called into question the utilitarianism-oriented human-wildlife relations and the legitimacy of wildlife protection regime in China. The pandemic has triggered significant, swift, and encompassing changes in policies. Drawing on insights from historical institutionalism, we argue that COVID-19 constitutes a critical juncture in China's wildlife protection policy.
\end{abstract}

Keywords COVID-19 $\cdot$ China $\cdot$ Wildlife protection

COVID-19, which erupted from a Wuhan wildlife market, may have originated in animals (Zhou, 2020). In response, China moved swiftly and issued an urgent decision to ban the consumption of all terrestrial wild animals, a move that was unprecedented in scope and scale (Koh et al., 2021). This legally binding decision was initiated and adopted by China's highest legislature and immediately set off a wave of legislative actions and impacts. COVID-19 could initiate a path of subsequent policies that dramatically increase the likelihood of more oversight and regulation of China's wildlife trade. Crises such as economic depressions, global pandemics and wars can bring about abrupt changes in institutions. In historical intuitionalism, such crises are understood as "critical junctures." Critical junctures are trigger events that set processes of institutional or policy change in motion during relatively short

This note belongs to the Topical Collection "Seeing Clearly Through COVID-19: Current and future questions for the history and philosophy of the life sciences", edited by G. Boniolo and L. Onaga.

Jing Xu

xujing15@xjtu.edu.cn

1 Department of Sociology, School of Humanities and Social Science, Xi'an Jiaotong University, Xi'an, China

2 College of Environmental Science and Engineering, Peking University, Beijing, China 
periods of time (Capoccia \& Kelemen, 2007; Hogan \& Doyle, 2007). COVID-19 constitutes a critical juncture with respect to wildlife protection in China.

Throughout Chinese history, animals have been interpreted or used for spiritual purposes or as an intellectual, economic, socio-political, or physical resource, and they also have been regarded as having moral values. Historically, human-wildlife relationships in China had multiple dimensions, including utilitarian, sentimental, and sympathetic attitudes—which often co-existed-toward animals (Harris, 1996; Sterckx et al., 2018). The utilitarian views concerning wildlife gained traction over others in the early 1960s when the country was faced with famine and a catastrophic economic downturn. Animals were actively utilized for their economic benefits, and the guiding principle of wildlife protection policies was to protect animals for their sustained use (Songster, 2018). Such utilitarian attitudes toward wildlife culminated in China's decades of rapid economic development after 1978. The Wildlife Protection Law (WPL) has long been interpreted in favor of "wildlife utilization," and the norm of "protection for human use" has become deeply embedded in the legislation, even though the law has been amended several times since it was first adopted in 1988 (Li, 2007; Xiao et al., 2021). However, COVID-19 has forced the Chinese to reflect on the impact of wildlife utilization and the way wildlife is valued, leading them to recognize that humans, wildlife, and public health are closely linked (Fang $\&$ Song, 2021). The utilitarianism-oriented and human-centered attitudes toward wildlife have thus come into question. It is a matter of urgency that all life, including animals, is understood as inherently worthy and that it is only together that we can create a whole, healthy, and harmonious community of living things. This philosophy on animals has begun to influence Chinese attitudes toward animals and their approaches to protecting wildlife. In a survey of Chinese public opinion on wildlife trade and consumption carried out in February 2020, 96.2\% favored legislation to ban the eating of wildlife, and $95.1 \%$ were in favor of legislation to prohibit the trading of wildlife and their products (Shi, 2020). After the COVID-19 outbreak, public opinion against wildlife utilization that is unsustainable, illegal, or carries significant risks to human health helped produce mandates for policy change.

The COVID-19 pandemic brought into question the selective protection of wildlife set by the WPL. It triggered heated debate among civil society and the academic community in China over its unequal and inadequate wildlife protection. A key point of discussion has been the limited scope of legal protection for wildlife. Under the WPL, there are only two categories of wildlife species that qualify for protection: (1) rare or endangered wildlife and (2) wildlife with significant ecological, scientific, or social value. The rest, which account for $40 \%$ of Chinese species, are outside the scope of legal protection (Xiao et al., 2021). From a utilitarian view, wildlife is differentiated according to rarity, risk of extinction, and instrumental value. However, from an ecological perspective, every species has a role to play in building ecological integrity. As far as public health is concerned, many species serve as reservoirs for zoonotic diseases, thereby posing a health risk to humans (Plourde et al., 2017). Research revealed that COVID-19 is associated with a new virus of probable bat origin (Zhou et al., 2020). However, wildlife species with a high risk of zoonosis, such as bats and marmots, are outside the narrow scope of the WPL. Hunting, trading, and eating such unprotected wildlife have been free from government regulation. 
Central to critical junctures is the significant, swift, and encompassing changes that occur in institutions or policies (Hogan, 2006). In response to COVID-19, China immediately changed its policy emphasis toward restricting wildlife utilization and protecting public health (You, 2020). On February 10, 2020, one and a half month after the novel coronavirus was identified, the National People's Congress (NPC) acted urgently to embark on revising the WPL. Two weeks later, the NPC enacted a complete ban on the consumption of terrestrial wildlife as food and the illegal trade of wildlife. Prior to the ban, only about 400 wildlife species, including Ailuropoda melanoleuca and Panthera tigris, were under special state protection and prohibited from being consumed for food, yet the purchase, sale, and utilization of all other field-harvested or artificially bred wildlife for commercial purposes, including food, were allowed. In that context, the commercial use of wildlife for fur, food, medicine, and exhibition in the country in 2016 generated 520.6 billion yuan (around US\$80 billion) in revenue with the employment of 14.09 million people, and the use of wildlife for food accounted for a large portion of this revenue (Chinese Academy of Engineering, 2017). COVID-19 instigated the ban that set off processes to reform the longstanding, utilizationoriented regime. The prohibition has been incorporated into the revised draft of the WPL. Before the WPL gets revised, local governments and administrative agencies at the national level have acted first. They swiftly adopted a wide array of laws and regulations to implement the ban throughout the country. This rapid policy change has an encompassing influence on the Chinese society. It affects the livelihood of millions of people engaged in the wildlife farming industry and causes huge economic losses. Moreover, it has an impact on hundreds of millions of ordinary people following millennia-old traditions of eating wildlife in China.

There are concerns that China's policy change is insufficient to protect public health from wildlife-associated diseases because wildlife is used for multiple purposes, not only for food but also for medicine, which is also risky in terms of zoonotic disease transmission (Wang, 2020). However, the pandemic created an initial impetus for policymakers to make a major shift in policy direction toward restricting wildlife utilization and preventing public health risks. We argue that this shift could set in motion a path of subsequent policies that substantially increase the likelihood of more restrictions and control on China's wildlife utilization. Therefore, the COVID-19 crisis potentially represents a critical juncture with lasting implications for wildlife protection policy in China.

Funding The work was supported by Xi' an Jiaotong University Research Grants No. SK2021021.

\section{Declaration}

Conflict of interest The authors declare that they have no conflict of interest. 


\section{References}

Capoccia, G., \& Kelemen, R. D. (2007). The study of critical junctures: Theory, narrative, and counterfactuals in historical institutionalism. World Politics, 59(3), 341-369.

Chinese Academy of Engineering. (2017). Report on sustainable development strategy of China's wildlife farming industry. Retrieved from December 27, 2020, http://www.cbcgdf.org/NewsShow/4854/ 11310.html.

Fang, G., \& Song, Q. (2021). Legislation advancement of one health in China in the context of the COVID-19 pandemic: From the perspective of the wild animal conservation law. One Health, 12(2021), 100195.

Harris, R. B. (1996). Approaches to conserving vulnerable wildlife in China: Does the color of cat matter-If it catches mice? Environmental Values, 5(4), 303-334.

Hogan, J. (2006). Remoulding the critical junctures approach. Canadian Journal of Political Science, 39(3), 657-679.

Hogan, J., \& Doyle, D. (2007). The importance of ideas: An a priori critical juncture framework. Canadian Journal of Political Science, 40(04), 883-910.

Koh, L. P., Li, Y., \& Lee, J. S. H. (2021). The value of China's ban on wildlife trade and consumption. Nature Sustainability, 4(1), 2-4.

Li, P. J. (2007). Enforcing wildlife protection in China: The legislative and political solutions. China Information, 21(1), 71-107.

Plourde, B. T., Burgess, T. L., Eskew, E. A., Roth, T. M., Stephenson, N., \& Foley, J. E. (2017). Are disease reservoirs special? Taxonomic and life history characteristics. PLoS ONE, 12(7), e0180716.

Shi, et al. (2020). Public perception of wildlife consumption and trade during the COVID-19 outbreak. Biodiversity Science, 28(5), 630-643 [in Chinese].

Songster, E. (2018). Panda nation: The construction and conservation of China's modern icon. . Oxford: Oxford University Press.

Sterckx, R., Siebert, M., \& Schäfer, D. (Eds.). (2018). Animals through Chinese History: Earliest Times to 1911. (1st ed.). Cambridge: Cambridge University Press.

Wang, H., et al. (2020). Wildlife consumption ban is insufficient. Science, 367(6475), 1435.

Xiao, L., Lu, Z., Li, X., Zhao, X., \& Li, B. V. (2021). Why do we need a wildlife consumption ban in China? Current Biology, 31(4), R168-R172.

You, M. (2020). Changes of China's regulatory regime on commercial artificial breeding of terrestrial wildlife in time of COVID-19 outbreak and impacts on the future. Biological Conservation, 250(2020), 108756.

Zhou, P., et al. (2020). A pneumonia outbreak associated with a new coronavirus of probable bat origin. Nature, 579(7798), 270-273.

Publisher's Note Springer Nature remains neutral with regard to jurisdictional claims in published maps and institutional affiliations. 